\title{
The more you have, the less you give? Prospective donation behavior for COVID-19 causes
}

\author{
Alexandra Maftei ${ }^{1}$ \\ I “Alexandru Ioan Cuza" University, Department of Psychology and Educational Sciences, Iasi, Romania
}

Received 24.04.2020; Received revised 11.06.2020; Accepted 24.06.2020;

Available online 30.06.2020

\begin{abstract}
Donation behavior is essential for non-profit organizations, especially during a health crisis, such as the current COVID-19 pandemic. The present study explored a series of associated factors of donor behavior, such as age, gender, income, education, and cause-related factors, in a sample of Romanian adults ( $N=168$, age range $20-78$ years old, $77 \%$ females). Our analyses suggested that the fundraising cause's emotional value, along with the fundraiser's public and personal implications, were the most relevant motivational factors for the donor's behavior. Age, income, and educational level were significantly associated with self-reported donation activity. In essence, younger participants with lower incomes and educational levels reported donating more money to NGOs, mostly to education-related causes. Finally, in a prospective donation task for one of the current COVID-19 related Non-Governmental Organizations' campaigns, results suggested that a) the higher the income, the lower the probability of donating, and b) the fundraising type of cause was significantly associated with prospective donation behavior. People who usually donated more to medical causes were the most likely to engage in altruistic behavior for coronavirus pandemicrelated issues. We discuss these preliminary results within the current coronavirus crisis and potential implications for both the non-profit and governmental sectors.
\end{abstract}

Keywords: fundraising, donation behavior, prospective altruism, COVID-19.

Address of correspondence Alexandra Maftei, Department of Psychology, Faculty of Psychology and Educational Sciences, Alexandru Ioan Cuza University of Iaşi, 3 Toma Cozma Street, Romania.

E-mail: psihologamaftei@gmail.com.

\section{Introduction}

The current COVID-19 pandemic is a significant, worldwide health and social crisis. At the time of writing (June 2020), more than 7.4 million people all over the planet were infected with the novel coronavirus, and more than 419.000 people died because of it. Governments worldwide are facing important issues with supplying the necessary protective gear, tracking population movement and compliance with new health and social regulation, and helping those in need. Therefore, Non-Governmental Organizations (NGOs) are more needed than ever. As Mahmood (2009) suggested more than ten years ago, during the H5N1 pandemic, NGOs "now have the opportunity and the responsibility to play a major role in preparedness, response, impact mitigation, and advocacy to lessen the consequences of pandemic influenza in the poorest nations and most vulnerable groups of people" (p.113)

\begin{abstract}
Along with private companies and political action groups, Romanian NGOs are actively involved in fundraising campaigns aimed to either procure the (lacking) necessary medical equipment, supplies, testing gear, or to support families in need, especially vulnerable children, women, and the elderly. According to data collected by the Association for Community and Relations, and presented in a preliminary report at the beginning of May 2020, over 80 non-governmental organizations managed, in seven weeks, to buy medical equipment and devices worth over 13.95 million euros for hospitals across the country (Ion, 2020). Though an exact number of people economically and socially affected by the COVID-19 pandemic is hard to estimate, preliminary data suggest that Romania and Greece are among the most financially affected countries in Europe (Hoikkala, 2020), while countries in Scandinavia seem to be the least affected. Since the pandemic exploits gaps and inequalities in health systems, emphasizing the importance of investing in health workers, infrastructure and health systems to prevent,
\end{abstract}


detect and respond to disease outbreaks, the most vulnerable groups (i.e., the poor, the elderly) are among the most affected. That is why, it is all the more important to explore potential correlations between the general characteristics of the Romanian donor and his/her potential involvement in fundraising campaigns, since NGOs are at the front line of protecting vulnerable groups.

Understanding donors' motivations and exploring the leading personal and demographic characteristics can lead to effective fundraising strategies that can both aim and retain donors (Sargeant \& Woodliffe, 2007). Consistent research has already shown that income plays a significant role in donation behavior. For example, higher-income donors are usually less likely to donate than lower-income individuals (Center on Philanthropy, 2009; Kasri, 2013). When it comes to gender differences in charitable giving, a consistent body of research showed that women are more likely to donate than men (Piper \& Schnepf, 2008). Older people tend to donate more compared to younger ones (Bekkers \& Wiepking, 2011), and findings related to educational level differences in donation behavior suggested that donors with a high level of education tend to donate more (Center on Philanthropy, 2009; Kasri, 2013; Turcotte, 2012).

Bekkers and Wiepking (2011) explored a series of mechanisms that drive people's donation behavior. Their findings suggested that awareness of need, solicitation, costs and benefits, altruism, reputation, psychological benefits, values, and efficacy are the most relevant factors in explaining charitable giving. Efficacy refers to "the perception of donors that their contribution makes a difference to the cause they are supporting" (Bekkers \& Wiepking, 2011, p.942). People are less likely to donate when they consider their contribution somewhat unable to make a difference, and this perception is related to the trust in charitable organizations. More specifically, the higher the trust in an NGO, the higher the perceived efficacy, and, consequently, the chances to donate for a specific cause.

An NGO's reputation, built on donors' confidence in the organization, is also vital for donating behavior. For example, Wiepking (2009) suggested that higher levels of confidence in charitable organizations generally increase the likelihood of donations. When a prestigious NGO or fundraiser solicits money for a specific cause, chances for donation behavior increase due to their status (Jackson \& Latané, 1981). The fundraisers' reputation and her/his subjective perception are also important. In essence, studies suggested that the lower the social (Bekkers, 2004) and personal distance (Schervish \& Havens, 1997) between the fundraiser and the potential donor, the higher the chances to donate.

The effect of emotions on donating behavior has been explored by various research, and findings confirmed their powerful impact. For example, guilt is often used in advertising donating campaigns, motivating subsequent donation behavior (Basil, Ridgway, \& Basil; De Hooge, Nelissen, \& Breugelmans, 2011; Hibbert, Smith, \& Davies, 2007). Anger and fear were also found to motivate charity donations (Bagozzi \& Moore, 1994; van Doorn, Zeelenberg, \& Breugelmans, 2017).

\section{The present study}

The present study aimed to explore a series of associated factors of donor behavior, such as age, gender, income, education, and cause-related factors, in a sample of Romanian adults, as well the engagement in a prospective COVID-19 donation task. Within the current pandemic, the awareness of need (i.e., the degree of need for help) is highly advertised. Therefore, we assumed the following: 1) people would be more likely to engage in a prospective donation task, compared to a typical situation (i.e., not a pandemic situation such as the present one), due to the degree of help imposed by the coronavirus health crisis (Bennett \& Kottasz, 2000; Cheung \& Chan, 2000; Lee \& Farrell, 2003; Levitt \& Kornhaber, 1977; Staub \& Baer, 1974); 2) the emotional impact of social causes (regardless of the emotion implied) would contribute the most to one's donation behavior intention to a COVID-19 cause (Basil, Ridgway, \& Basil; Bagozzi \& Moore, 1994; De Hooge, Nelissen, \& Breugelmans, 2011; Hibbert, Smith, \& Davies, 2007; van Doorn, Zeelenberg, \& Breugelmans, 2017), as well as in self-reported retrospective donation behavior; 3) older particicpants, with lower-incomes and higher education levels, would report a higher donor behavior frequency in both general (retrospective) and prospective donation tasks (Breeze et al., 2005; Center on Philanthropy, 2009; Sargeant \& Woodliffe, 2007); and, finally, 4) we expected significant differences in both the general and the prospective donation behavior between females and males, with higher scores within the female sample (Piper \& Schnepf, 2008).

\section{Method}

\section{Participants}

A convenient sample of 168 Romanian adults participated in our study. Their age varied from 20 to 78 years old. Table 1 offers a detailed perspective on participants' age, gender, education level, and monthly income.

Table 1. Demographic characteristics of the research sample

\begin{tabular}{|c|c|c|c|c|c|}
\hline Variables & $\mathrm{N}$ & $M$ & $S D$ & $\%$ & \\
\hline Age & 168 & 40.83 & 11.57 & & \\
\hline \multicolumn{6}{|l|}{ Gender } \\
\hline Male & 38 & & & $22.6 \%$ & \\
\hline Female & 130 & & & $77.4 \%$ & \\
\hline $\begin{array}{l}\text { Monthly } \\
\text { income }\end{array}$ & $\begin{array}{c}<300 \\
4\end{array}$ & $\begin{array}{c}300- \\
500\end{array}$ & $\begin{array}{c}500- \\
700\end{array}$ & $\begin{array}{l}700- \\
900\end{array}$ & $\begin{array}{c}>900 \\
98\end{array}$ \\
\hline (€) & $(2.4 \%)$ & $\begin{array}{c}9 \\
(5.4 \%)\end{array}$ & $\begin{array}{c}22 \\
(13.1 \%)\end{array}$ & $\begin{array}{c}35 \\
(20.8 \%)\end{array}$ & $(58.3 \%)$ \\
\hline $\begin{array}{l}\text { Education } \\
\text { level }\end{array}$ & $\mathrm{U}$ & B & M & Ph.D & \\
\hline $\begin{array}{l}\mathrm{N} \\
\%\end{array}$ & $\begin{array}{c}32 \\
(19 \%)\end{array}$ & $\begin{array}{c}62 \\
(36.9 \%)\end{array}$ & $\begin{array}{c}34 \\
(20.2 \%)\end{array}$ & $\begin{array}{c}40 \\
(23.8 \%)\end{array}$ & \\
\hline
\end{tabular}

Note: $U=$ undergraduate; $B=$ Bachelor's degree; $M=$ Master's degree.

\section{Procedure}

Data were collected at the beginning of April 2020. A consent form presented the study's primary objective as being related to the general online behavior within the pandemic context. It is important to mention that our research was conducted three weeks after the Romanian government imposed a series of social and health measures to prevent the spread of the SARS-CoV-2 virus (COVID19). We advertised the survey using social media groups, designed to raise awareness for local and national NGOs, and advertise various fundraising campaigns.

All participants were informed of their right to withdraw from the study at any time, and that all the data they provided would be kept confidential. Our study was non-experimental and cross-sectional, and the testing 
procedure took around ten minutes. The research was conducted following the ethical standards of the responsible committees on human experimentation and with the 2013 Helsinki Declaration.

\section{Measures}

We developed a scale to explore participants' general behavior related to donating to NGOs (Appendix A). Within the scale, we measured participants' self-reported general donating behavior, using the following item: Do you usually donate to NGOs, participants answering on a dichotomic scale, with Yes or No as possible answers. We also assessed the ways participants usually donated (Which are the ways you usually donate?), proving four potential answers: via fundraising events, social media platforms, mobile services (SMS), or other ways that participants subsequently detailed. One item of the scale explored the most frequent reason for donations (i.e., What is the criterion that usually convince you to make a donation?), participants choosing between five different answers: the emotional implication of the cause, the NGO's prestige, the perceived importance of the cause, the perceived power of the message, or the fundraising campaign's visibility.

We further asked participants to what type of cause they usually donated money to NGOs for, providing them with a list of six potential answers: education-related causes (i.e., equipping schools, renovating buildings for students, providing school materials for all children, access to education for low-income children); medical-related causes (i.e., equipping hospitals, ensuring missing medicines in medical units, blood donation campaigns, funding research for treating cancer); social causes (i.e., social care for vulnerable people - children, the poor, the elderly, help children living in harsh economic conditions, help for needy families, anti-discrimination campaigns, fighting poverty and hunger); religious causes (i.e., church renovation, direct donations to churches) and, finally, cultural causes (i.e., supporting culture through direct donations to companies with an artistic profile, restoration campaigns of cultural monuments, donations to artists).

Afterward, participants were asked which is the most important quality in a fundraiser, that would significantly contribute to their personal donating motivation. They chose their answers from a scale with five pre-determined answers: popularity and trustworthiness; active involvement in and for the cause; his/her personal connection to me; his/her access to various communities; constant involvement in fundraising activities.

Finally, participants estimated the likelihood of a prospective donation to NGOs involved in COVID-19related causes (How would you rate the probability for you to donate to an NGO, for a COVID-19 related cause, in the near future?) on a Likert type scale ranging from 1 (very low) to 5 (very high). A series of demographic questions assessed participants' age, gender, education level, and monthly income.

\section{Results}

We used the 20.0 version of the SPSS program to analyze our data. Frequency analyses suggested that participants in our sample usually donated for NGO campaigns $(73.2 \%)$. Generally, participants donated the most for education-related campaigns $(44 \%)$, followed by social causes $(33.9 \%)$ and medical causes $(17.9 \%)$. One of our most relevant findings was related to the most important factor that motivated our participants' donation behavior, namely the emotional impact of the cause $(51.8 \%)$ and the perceived importance of the cause (26.8\%). Also, most people considered the fundraiser's involvement as being the most valuable quality in a fundraiser $(50.6 \%)$, followed by her or his credibility in terms of popularity and trustworthiness $(23.8 \%)$. In terms of COVID-19 prospective donation behavior, most of the participants in our sample mostly reported a moderate intent to donate $(33 \%)$. Table 2 offers a comprehensive image of our findings related to our participants' selfreported donation behavior.

Table 2. Self-reported donation behavior and associated factors $(N=168)$

\begin{tabular}{|c|c|c|}
\hline Variables & $\mathrm{N}$ & $\%$ \\
\hline \multicolumn{3}{|l|}{ Do you usually donate to NGOs? } \\
\hline${ }^{2}$ & 123 & 73.2 \\
\hline No & 45 & 26.8 \\
\hline \multicolumn{3}{|l|}{$\begin{array}{l}\text { Which are the causes you usually donate for to } \\
N G O s \text { ? }\end{array}$} \\
\hline $\begin{array}{lll}\text { Educational }\end{array}$ & 74 & 44 \\
\hline Medical & 30 & 17.9 \\
\hline Social & 57 & 33.9 \\
\hline Religious & 3 & 1.8 \\
\hline Cultural & 4 & 2.4 \\
\hline \multicolumn{3}{|l|}{$\begin{array}{l}\text { Which is the most important factor that } \\
\text { determines you to donate to NGOs? }\end{array}$} \\
\hline Emotional impact & 87 & 51.8 \\
\hline Importance of the fundraising's cause & 45 & 26.8 \\
\hline The NGO's prestige & 12 & 7.1 \\
\hline $\begin{array}{r}\text { Importance of the fundraising's cause } \\
\text { message }\end{array}$ & 15 & 8.9 \\
\hline Fundraising campaign's visibility & 9 & 5.4 \\
\hline \multicolumn{3}{|l|}{$\begin{array}{l}\text { Which is the most important quality in a } \\
\text { fundraiser? }\end{array}$} \\
\hline Popularity and trustworthiness & 40 & 23.8 \\
\hline Active involvement in and for the cause & 85 & 50.6 \\
\hline His/her personal connection to me & 16 & 9.5 \\
\hline His/her access to various communities & 11 & 6.5 \\
\hline $\begin{array}{r}\text { Constant involvement in fundraising } \\
\text { activities }\end{array}$ & 16 & 9.5 \\
\hline \multicolumn{3}{|l|}{$\begin{array}{l}\text { How would you rate the probability for you to } \\
\text { donate to a NGO, for a COVID-19 related } \\
\text { cause, in the near future? }\end{array}$} \\
\hline Very low & 20 & 11.9 \\
\hline Low & 37 & 22.0 \\
\hline Moderate & 56 & 33.3 \\
\hline High & 37 & 22.0 \\
\hline Very High & 18 & 10.7 \\
\hline
\end{tabular}

Correlation analyses revealed significant associations between participants' age, income, education level, and both general and prospective donation behavior. Our results suggested a significant, negative association between the general donation behavior and education level $(\mathrm{r}=-.176, \mathrm{p}=.023)$, as well as with age $(\mathrm{r}=-.219, \mathrm{p}=.004)$. More specifically, the higher the age and income, the lower the probability of donating to NGOs' fundraising campaigns. The probability of donating for a COVID-19 NGO campaign negatively correlated with participants' income $(\mathrm{r}=-.488, \mathrm{p}<.001)$. We did not find any significant correlations between the prospective donation behavior to COVID-19 related causes and age $(\mathrm{r}=-.121, \mathrm{p}=.118)$, education level $(\mathrm{r}=-.142, \mathrm{p}=.067)$, or the general donation behavior $(\mathrm{r}=-.010, \mathrm{p}=.898)$. Table 3 presents the means, standard deviations, and correlations between the variables.

In order to deepen our exploration, we further performed Independent Chi-square tests to analyze the associations between the fundraising cause (educational, 
medical, social, cultural, or religious) and participants' general and prospective donation behavior. We found no significant association between the cause-domain and general donation behavior $(p=.169)$. However, we did find significant association between the nature of the cause people usually donate for, and the prospective intention to donate to a COVID-19 campaign: $\chi 2(16)=50.38, \mathrm{p}<.001$. Thus, participants who generally donated to medical causes reported the highest probability of donating in the prospective COVID-19 donation task. We also performed Independent Chi-square tests to analyze the associations between the prospective COVID-19 donation behavior and the criterion that generally accounted for participants' donation behavior, and results showed no significant associations $\chi 2(16)=6.38, p=.983$. We also found a lack of significance between the prospective COVID-19 donation behavior and the fundraiser's characteristics $\chi 2$ $(16)=14.50, p=.561$.

\begin{tabular}{llllllll}
\hline \multicolumn{1}{l}{ Table 3. Means, standard deviations and correlations between the variables } \\
\hline 1. Age & M & SD & 1 & 2 & 3 & 4 & 5 \\
2. Education level & 40.83 & 11.57 & 1 & & & & \\
3. Income & 2.48 & 1.05 & $.206^{* *}$ & 1 & & & \\
4. Prospective donation & 4.27 & 1.03 & .134 & $.355^{* *}$ & 1 & & \\
5. General donation behavior & 2.97 & 1.16 & -.121 & -.142 & $-.488^{* *}$ & 1 & \\
\hline
\end{tabular}

**. Correlation is significant at the 0.01 level (2-tailed).

*. Correlation is significant at the 0.05 level (2-tailed).

Finally, we explored the potential differences between males and females, in both general and prospective COVID-19 donation behavior. Wilcoxon tests suggested no significant difference in terms of general donation behavior ( $U=2287, p=.366$ ), nor future engagement in COVID-19 donations $(\mathrm{U}=2430, \mathrm{p}=.876)$.

\section{Discussion}

As far as we know, the current research is the first to explore the relationship between the general characteristics of donation behavior, along with a series of associated variables (i.e., age, gender, income, education, and causerelated factors), and prospective engagement in Romanian NGOs COVID-19 campaigns. Several studies explored predictors and associated factors related to the importance of the fundraising cause's message, fundraising campaigns' visibility and leaders, and various demographical variables. However, our pilot study would be the first to explore these associations in the COVID-19 pandemic context, within a sample of Romanian adults.

We assumed that people would be more likely to engage in a prospective donation task, compared to a typical situation (i.e., not a pandemic), because of the health and socio-economic crisis generated by the coronavirus (e.g., Cheung \& Chan, 2000; Lee \& Farrell, 2003). However, the percentages were higher among the self-reported general donation behavior (73\%), compared to the prospective COVID-19 donation percentages, infirming our assumption. Moreover, it is also important to notice that participants in our sample first reported their previous donation behavior, and then estimated the probability to engage in a prospective one. Within this context, the Cognitive Dissonance Theory (Festinger, 1957), which emphasizes people's need for consistency in both their thoughts and behavior, should be taken into consideration: it is possible that our participants' answers may be biased by their previous answers on the general donation self-reported answers. Future studies should counter-balance the order of the questions we used, in order to test the reliability of the scale we used.

We also assumed that the emotional impact of social causes (regardless of the emotion implied) would contribute the most to both prospective and retrospective donation behavior, in line with previous research in the area (e.g., De Hooge, Nelissen, \& Breugelmans, 2011; van Doorn, Zeelenberg, \& Breugelmans, 2017). Our assumption was confirmed: within our sample, the most important factor (related to the cause) endorsed for donation behavior was emotional involvement (i.e., the emotional impact of the cause). Still, most participants chose the middle point of the scale, aiming for a rather neutral approach than an assumed perspective of their involvement in supporting the NGOs engaged in the COVID-19 fight. Similar percentages (22\%) chose either the "low" or the "high" probability.

One of the alternative pathways in explaining the current results lies within the moral licensing theory, which could be an interesting future direction. People might consider the lockdown measures (and, implicitly, their forced compliance to its rules) as moral credits (Monin \& Miller, 2001), which are daily gathered and stored in their moral bank account. Since their moral balance is already lacking equilibrium (their daily behavior gathers more and more moral credits, waiting to be spent), we can explain their rather neutral prospective altruistic engagement as the result of overload in their perceived morality, namely because of the current pandemic. In other words, people might think, "I am already good [i.e., I obey the "pandemic" rules]; therefore, I do not need to express a moral intention; I already proved my morality". Therefore, future studies might want to extend this research direction in larger samples, and using an appropriate experimental design.

In line with previous research (e.g., Breeze et al., 2005; Sargeant \& Woodliffe), we also hypothesized that older participants, with lower-incomes and higher education levels, would engage more in a prospective COVID-19 donation task. However, we only found a significant link between participants' prospective COVID-19 donation intensions and income, and no significant associations with neither age, nor education. Moreover, our assumption related to gender differences in prospective donation to COVID-19 NGO-causes was also not confirmed. One of the main explanations we are considering is related to the complex, unforeseen, and surprising nature of the SARSCoV-2 pandemic. The participants in our group belong to a generation that has never encountered, at least in Romania, 
such restrictive conditions, imposed by such a high medical/health danger. Therefore, the exceptional character of the situation, which can generate a pronounced state of anxiety, might be one of the explanations underlying the counterintuitive results we obtained within the current sample.

Moreover, due to its novel character and the lack of information on its appearance and treatment, a lot of conspiracy beliefs emerged around COVID-19. Research has already showed that societal crisis situations, such as the current pandemic are thought to increase people's proneness to conspiracy and skeptical attitudes, namely due to the fear, uncertainty, and the lack of control they bring to one's daily routine (van Prooijen \& Douglas, 2017). Consequently, people may experience a lack of trust in COVID-19 campaigns, even though they unserstand their use and importance. Future studies may want to explore this alternative causal route adn deepen the associated results within COVID-19-related donation contexts.

Another interesting explanation for our results related to the prospective donation to COVID-19 causes lies within an idea previously explored by Västfjäll, Slovic, Mayorga, and Peters (2014). Their research suggested that individuals' capacity to feel sympathy or compassion for people in need is limited. We are more likely to donate to help or save one child, for example, and less likely to get involved when this number increases. Within the current pandemic, NGOs advocate for extremely high numbers of people: hundreds of people and need and thousands that could be saved with donated money for medical supplies and equipment, for example. According to Västfjäll, Slovic, Mayorga, \& Peters (2014), this particular high number of potential beneficiaries may be the reason behind a lack of involvement in donation behavior. This theory, along with our findings, contradicts recent, preliminary findings related to the effectiveness of moral messages on public health behavioral intentions during the pandemic (Everett, Colombatto, Chituc, Brady, \& Crockett, 2020). Everett and his collaborators suggested that utilitarian messages, emphasizing the greater good would be more effective than deontological ones (such as the ones suggested by Västfjäll et al., 2014). Future studies may want to explore the two theories concerning donation behavior outcomes.

A series of limits need to be addressed for the current research. First, our sample is rather small, and future studies should explore related findings on more extensive and more representative samples. Second, all our measures were self-reported, and social desirability may have interfered with our results. It is also worth to mention the potential impact of personal experience with COVID-19 as an important limitation to our study. We did not assess participants' experience with, for example, victims of the coronavirus. Another important limitation is related to the answers participants had to choose from, when answering the scale's items. It is possible that the choices we provided may have biased our participants' answers. Future studies may want to explore the current associations using openend questions, that might provide additional, different explanations and characteristics for general donation behavior to NGOs.

The paradox of giving less when one has more can be explained through various theories. People who have less are generally focused on the outside and the present time. In contrast, those who have more are more future-oriented and tend to focus on themselves - their self-centered perspectives determining solipsistic tendencies (e.g., Guthrie, Butler, \& Ward, 2009; Osman, Lv, \& Proulx, 2018). Still, we assumed that the extraordinary context of the pandemic would significantly impact these predictions, and elevate people's prospective altruistic engagement by donating to NGOs' COVFI-19 campaigns. Our assumption was not confirmed, though, suggesting apparent stability in people's donation intentions. Finally, we already know that people who have relatives or close friends suffering from a specific illness are generally more likely to donate to organizations involved in fighting those specific illnesses (Bekkers, 2008). Therefore, future studies may want to explore this potential connection. Further studies may also benefit from exploring the prospective moral licensing paradigm (Cascio \& Plant, 2015), by adding an actual donation task to the prospective one and, therefore, create an experimental design. Also, important variables such as trust the cultural environment in the context of NGO's credibility may have to be accounted for, as previous research already showed its impact on people's general donation behavior.

Despite these limitations, our research's contribution is highly practical, with less theoretical insights. Although we do contribute to the general knowledge of donation behavior, particularly among Romanians, our findings are mostly valuable for their insights within the current pandemic crisis. NGOs, as well as private and governmental entities, need to find the most effective ways to motivate one's moral behavior, regardless of its type: money donations, voluntary service for the elderly, active involvement in medical units, or civic engagement. Our results may bring important insights for future fundraising campaigns, such as the importance of cause-related motivations.

\section{Conflicts of interest}

The authors declare that there is no conflict of interest.

\section{Acknowledgements}

I would like to thank Miss. Maria Marchis for her active contribution in gathering the data, and her valuable research ideas for the present study.

\section{References}

Bagozzi, R.P., Moore, D.J. (1994). Public service advertisements: Emotions and empathy guide prosocial behavior. Journal of Marketing 58(1): 56-70.

Basil, D.Z., Ridgway, N.M., \& Basil, M.D. (2008). Guilt and giving: A process model of empathy and efficacy. Psychology \& Marketing, 25(1), 1-23.

Bekkers, R. (2008). Straight from the heart. In S. Chambré \& M. Goldner (Eds.), Advances in medical sociology, Volume 10: Patients, consumers, and civil society: US andinternational perspectives (pp. 197-221): Emerald Group.

Bekkers, R. H. F. P., \& Wiepking, P. (2011). Who gives? A literature review of predictors of charitable giving. Religion, education, age, and socialization. Voluntary Sector Review, 2(3), 337-365. https://doi.org/10.1332/204080511x6087712.

Bekkers, R., \& Wiepking, P. (2011). A Literature Review of Empirical Studies of Philanthropy: Eight Mechanisms That Drive Charitable Giving. Non-profit and Voluntary Sector Quarterly, 40(5), 924-973. DOI: $10.1177 / 0899764010380927$. 
Bennett, R., \& Kottasz, R. (2000). Emergency fundraising for disaster relief. Disaster Prevention and Management, 9, 352-359.

Cascio, J., \& Plant, A. (2015). Prospective moral licensing: Does anticipating doing good later allow you to be bad now? Journal of Experimental Social Psychology, 56, 110-116. 10.1016/j.jesp.2014.09.009.

Center on Philanthropy (2009). Understanding Donor Motivations for Giving. New York: CCS

Cheung, C. K., \& Chan, C. M. (2000). Social-cognitive factors of donating money to charity, with special attention to an international relief organization. Evaluation and Program Planning, 23, 241-253.

De Hooge, I.E., Nelissen, R.M.A., \& Breugelmans, S.M. (2011). What is moral about guilt? Acting 'prosocially' at the disadvantage of others. Journal of Personality and Social Psychology 100(3): 462-473.

Everett, J. A. C., Colombatto, C., Chituc, V., Brady, W. J., \& Crockett, M. (2020, March 20th). The effectiveness of moral messages on public health behavioral intentions during the COVID-19 pandemic. https://doi.org/10.31234/osf.io/9yqs8.

Guthrie, L. C., Butler, S. C., \& Ward, M. M. (2009). Time perspective and socioeconomic status: a link to socioeconomic disparities in health? Social Science \& Medicine, 68(12), 2145-2151. https://doi.org/10.1016/j.socscimed.2009.04.004.

Hibbert, S., Smith, A., \& Davies, A. (2007). Guilt appeals: Persuasion knowledge and charitable giving. Psychology and Marketing, 24(8), 723-742.

Hoikkala, H. (2020). Greece Sees Biggest Decline in Financial Wellbeing in Europe. Retrieved from https://www.bloomberg.com/news/articles/2020-0609/greece-sees-biggest-decline- in-financialwellbeing-in-europe.

Ion, R. (2020). De la inceputul crizei COVID-19, ONG-urile din România au dotat spitalele cu echipamente şi aparatură în valoare de 14 milioane de euro (Since the beginning of the COVID-19 crisis, Romanian NGOs have equipped hospitals with equipment and medical gear worth 14 million euros). Retrieved from https://republica.ro/de-la-inceputul-crizei-covid-19-ongurile-din-romania-au-dotat-spitalele-cu-echipamente-siaparatura-in.

Jackson, J. M., \& Latané, B. (1981). Strength and number of solicitors and the urge towardaltruism. Personality and Social Psychology Bulletin, 7, 415-422.

Kasri, R. A. (2013). Giving behaviors in Indonesia: motives and marketing implications for Islamic charities. Journal of Islamic Marketing, 4, 306-324.

Lee, B. A., \& Farrell, C. R. (2003). Buddy, can you spare a dime? Homelessness, panhandling, and the public. Urban Affairs Review, 38, 299-324.
Levitt, L., \& Kornhaber, R. C. (1977). Stigma and compliance. A re-examination. Journal of Social Psychology, 103(1), 13-18.

Mahmood, J. (2009). Pandemic preparedness in Asia. (Caballero- Anthony M., Ed.). S. Rajaratnam School of International Studies. Retrieved April 19th, 2020, from https://www.rsis.edu.sg/wpcontent/uploads/2014/07/ER09 0113_Pandemic_Preparedness_Asia.pdf

Monin, B., \& Miller, D.T. (2001). Moral Credentials and the Expression of Prejudice. Journal of Personality and Social Psychology, 81, 33-43. DOI: 10.1037//0022-3514.8I.I.33.

Osman, M., Lv, J.-Y., \& Proulx, M. J. (2018). Can empathy promote cooperation when status and money matter? Basic and Applied Social Psychology, 40(4), 201-218. https://doi.org/10.1080/01973533.2018.1463225.

Piper, G., \& Schnepf, S. (2008). Gender Differences in Charitable Giving in Great Britain. International Journal of Voluntary and Non-profit Organizations, 19(2),103124. DOI: $\quad 10.1007 / \mathrm{s} 11266-008-9057-9$.

Sargeant, A., \& Woodlife, L. Gift giving: an interdisciplinary review. International Journal of Nonprofit and Voluntary Sector Marketing, 12(4), 275-307. https://doi.org/10.1002/nvsm.308.

Schervish, P. G., \& Havens, J. J. (1997). Social participation and charitable giving: A multivariate analysis. Voluntas, 8 , 235-260.

Sokolowski, S. W. (1996). Show me the way to the next worthy deed: Towards a microstructural theory of volunteering and giving. Voluntas, 7, 259-278.

Staub, E., \& Baer, R. S. (1974). Stimulus characteristics of a sufferer and difficulty of escape as determinants of helping. Journal of Personality and Social Psychology, 30, 279-284.

van Doorn, J., Zeelenberg, M., \& Breugelmans, S. M. (2017). The impact of anger on donations to victims. International Review of Victimology, 23(3), 303-312. https://doi.org/10.1177/0269758017710819.

van Prooijen, J.-W., \& Douglas, K. M. (2017). Conspiracy theories as part of history: The role of societal crisis situations. Memory Studies, 10(3), 323-333. https://doi.org/10.1177/1750698017701615.

Västfjäll, D., Slovic, P., Mayorga, M., Peters, E. (2014) Compassion Fade: Affect and Charity Are Greatest for a Single Child in Need. PLOS ONE, 9(6). e100115. https://doi.org/10.1371/journal.pone.0100115.

Wiepking, P., \& Maas, I. (2009). Resources that make you generous: Effects of human andsocial resources on charitable giving. Social Forces, 86, 1973-1996. 